\title{
ANALISA SISTEM INFORMASI PELAPORAN PEREKAMAN FAKTUR PAJAK SECARA ONLINE PADA PT. SEMICRON INTI MUDA
}

\author{
Hasanudin 1), Endang Wahyudi ${ }^{2)}$, A.A Gede Ajusta ${ }^{3)}$, Lidya Salvina Helling ${ }^{4)}$ \\ Universitas Bina Sarana Informatika, Jakarta \\ Email : $\underline{\text { hasanudin.hnu@bsi.ac.id }}{ }^{1)} \underline{\text { endang.edw@bsi.ac.id }}{ }^{2)}$,a.gede.age@bsi.ac.id ${ }^{3)}$,lydia.lsh@bsi.ac.id ${ }^{4)}$
}

\begin{abstract}
Abstrak
Pelaporan Pajak PPN melalui aplikasi e-Faktur dari Direktoran Jendral Pajak diawali dari pembuatan faktur pajak yang benar. Hal tersebut dapat tercapai apabila seorang accounting staff menguasai dengan baik system aplikasi e-faktur tersebut dan juga diperlukan system informasi pembuatan faktur di perusahaan, agar dapat meminimalisir kesalahan-kesalahan baik disebabkan oleh human eror ataupun dari kelemahan aplikasi e-faktur tersebut. Banyak masalah dalam pembuatan faktur yang harus diketahui diantaranya aplikasi memerlukan koneksi internet yang baik, tidak menguasai aplikasi efaktur sampai dengan eror di server DJP sendiri. Hal tersebut dapat di minimalisir dengan system informasi yang baik di perusahaan. Dalam jurnal ini kami mempelajari dan menganalisa ssstem informasi perekaman e-faktur untuk mempelajari system pembuatan efaktur dan menganalisa permasalahn yang ada serta memberikan solusi apabila diperlukan. Adapun kesimpulannya adalah bahwa dalam pembuatan faktur pajak di perusahaan ini masih mengalamai beberapa masalah, diantaranya adalah : Kurang telitinya administrasi dalam menginput pada saat rekam faktur pajak baru, dalam kegiatannya sistem yang digunakan bergantung pada system online resmi Direktorat Jendral Pajak, sehingga dapat memakan waktu yang lama, Pada sistem berupa aplikasi online memerlukan jaringan internet, dimana terkadang jaringan mengalami error, permintaan barang khusus untuk barang yang akan dijadikan stok, harus IC yang melakukan pemesanan sehingga proses datang ke toko lebih lama, dan kurangnya informasi yang diberikan oleh petugas.
\end{abstract}

Kata kunci: sistem informasi, perekaman e-faktur, dewan faktur pajak.

\begin{abstract}
VAT Tax Reporting through the e-Invoice application from the Directorate General of Taxes starts from making the correct tax invoice. This can be achieved if an accounting staff masters the e-invoicing application system well and also requires an invoice making information system in the company, so as to minimize errors either caused by human error or from the weaknesses of the e-invoicing application. Many problems in making invoices that must be known include the application requires a good internet connection, not mastering the application of the fracture until the error on the DJP server itself. This can be minimized by a good information system in the company. In this journal, we study and analyze the information system for recording e-invoices to study the manufacturing system of the fracture and analyze the existing problems and provide solutions if needed. The conclusion is that in making tax invoices in this company there are still some problems, including: Lack of administration in inputting when recording a new tax invoice, the system used depends on the official online system of the Directorate General of Taxes, so it can take time a long time, the system in the form of an online application requires an internet network, where sometimes the network experiences errors, requests for special items for goods to be stocked, ICs must place an order so that the process of coming to the store is longer, and the lack of information provided by the officer..
\end{abstract}

Keywords: information system, invoice recording, and tax invoice 


\section{PENDAHULUAN}

Dimasa yang serba modern dan cepat ini penggunaan komputer serta sistem-sistemnya sudah menjadi kebutuhan utama dalam rangka meningkatkan sistem kerja perusahaan. Dalam suatu kegiatan usaha, baik itu perusahaan yang besar, menengah atau kecil tujuan utamanya adalah untuk memperoleh laba atau keuntungan usaha dalam menjaga kelangsungan usahanya.

Dengan adanya sistem komputer diharapkan perusahaan dapat memantau tahapan-tahapan yang telah dijalankan serta yang masih akan dilakukan dalam proses perekaman faktur. Dengan sistem perekaman faktur yang tertata dengan baik dan peralatan yang mendukung maka dapat meningkatkan efisiensi pada perusahaan tersebut.

Adapun beberapa masalah yang dihadapi oleh PT. Semicron Inti Muda yaitu sistem komputerisasi yang dipakai terhubung ke server jaringan pajak lainnya, sehingga ketika sedang melakukan perekaman harus terhubung ke sistem lainnya yang ada di pajak, sistem pun tidak dapat dijalankan/ digunakan jika tidak tehubung ke sistem lainnya.

Berdasarkan latar belakang diatas, maka penulis berkeinginan melakukan analisis sistem informasi perekaman faktur pada PT. Semicron Inti Muda dalam menjalankan aktivitas rekam faktur. Sehingga penulis mengangkat judul " ANALISA SISTEM INFORMASI PELAPORAN PEREKAMAN FAKTUR PAJAK SECARA ONLINE PADA PT. SEMICRON INTI MUDA".

\section{RUMUSAN MASALAH}

Rumusan masalah dalam penelitian ini adalah membahas analisa system berjalan pada perusahaan dan analisa permasalahan yang ada dan kepadanya diberikan suatu usulan perbaikan system jika atas segala permasalahan yang ada.

Batasan ruang lingkup pada istem informasi pelaporan rekam faktur untuk PT. Semicron Inti Muda adalah :
1. Prosedur rekam faktur mencakup kegiatan system yang dipakai

2. Prosedur pelaporan faktur pajak

3. Prosedur pendataan barang masuk mencakup laporan barang masuk.

4. Prosedur pembayaran faktur.

\section{TINJAUAN PUSTAKA}

\section{Pengertian Informasi}

Pengertian menurut Krismaji (2015:14), Informasi adalah "data yang telah diorganisasi dan telah memiliki kegunaan dan manfaat".Hal serupa disampaikan oleh Romney dan Steinbart (2015:4) :Informasi (information) adalah data yang telah dikelola dan diproses untuk memberikan arti dan memperbaiki proses pengambilan keputusan.

\section{Pengertian Sistem Informasi}

Menurut Al-Bahra (2013:13) Sistem informasi dapat didefinisikan sebagai berikut :

a. Suatu sistem yang dibuat oleh manusia yang terdiri dari komponenkomponen dalam organisasi untuk mencapai suatu tujuan yaitu menyajikan informasi.

b. Sekumpulan prosedur organisasi yang pada saat dilaksanakan akan memberikan informasi bagi pengambil keputusan dan/atau untuk mengendalikan organisasi.

c. Suatu sistem di dalam suatu organisasi yang mempertemukan kebutuhan pengolahan transaksi, mendukung operasi, bersifat manajerial.

\section{Pengertian Faktur Pajak}

Faktur Pajak adalah bukti pungutan pajak Pengusaha Kena Pajak (PKP), yang melakukan penyerahan Barang Kena Pajak (BKP) atau penyerahan Jasa Kena Pajak (JKP). PKP adalah bisnis/perusahaan/pengusaha yang melakukan penyerahan barang kena pajak dan/atau JKP yang dikenai Pajak Pertambahan Nilai (PPN). Adapun Jenis-jenis faktur pajak : 

a. Faktur Pajak Keluaran.
b. Faktur Pajak Masukan.
c. Faktur Pajak Pengganti.
d. Faktur Pajak Gabungan.
e. Faktur Pajak Digunggung.
f. Faktur Pajak Cacat.
g. Faktur Pajak Batal

\section{Faktur Pajak Elektronik}

Faktur pajak berbentuk elektronik, yang selanjutnya disebut e-faktur, adalah Faktur Pajak yang dibuat melalui aplikasi atau sistem elektronik yang ditentukan dan/atau disediakan oleh Direktorat Jenderal Pajak. Pemerintah menerbitkan adanya faktur pajak elektronik (e-faktur) dengan tujuan memberikan kemudahan, kenyamanan dan keamanan bagi PKP (Pengusaha Kena Pajak) dalam melaksanakan kewajiban perpajakannya khususnya pembuatan faktur pajak.

\section{Diagram Activity Sistem Berjalan}

Diagram activity system berjalan terdapat 2 jenis yaitu Use case Diagram dan Activity Diagram. seperti yang ada di daftar symbol, dengan penjelasan sebagai berikut :

\section{a. Use case diagram}

Use case diagram atau diagram use case merupakan pemodelan untuk menggambarkan kelakuan (behavior) sistem yang akan dibuat. Diagram use case mendeskripsikan sebuah interaksi antara satu atau lebih aktor dengan sistem yang akan dibuat. Terdapat beberapa simbol dalam menggambarkan diagram use case:

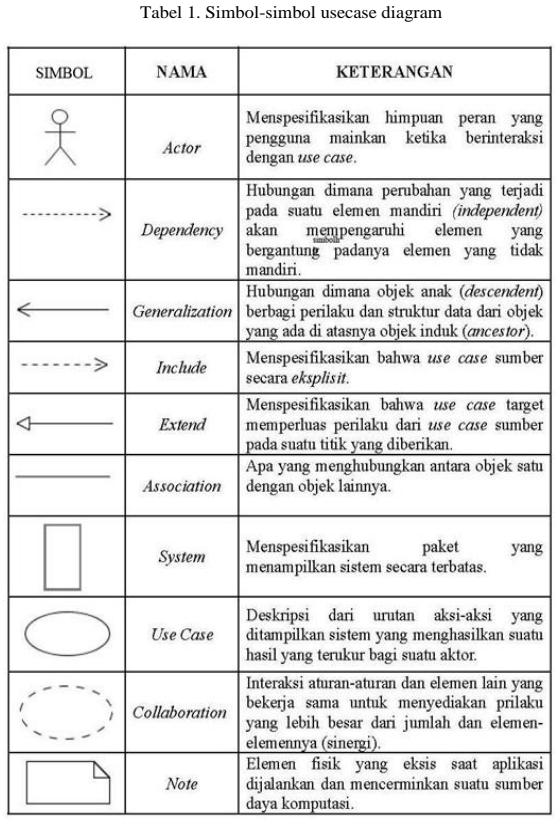

Sumber: www.kajianpustaka.com

\section{b. Activity Diagram}

Activity Diagram adalah diagram yang menggambarkan workflow (aliran kerja) atau aktivitas dari sebuah sistem atau proses bisnis. Yang perlu diperhatikan adalah bahwa diagram aktivitas menggambarkan aktivitas sistem bukan apa yang dilakukan aktor, jadi aktivitas yang dapat dilakukan oleh sistem.

Terdapat beberapa simbol dalam menggambarkan diagram use case :

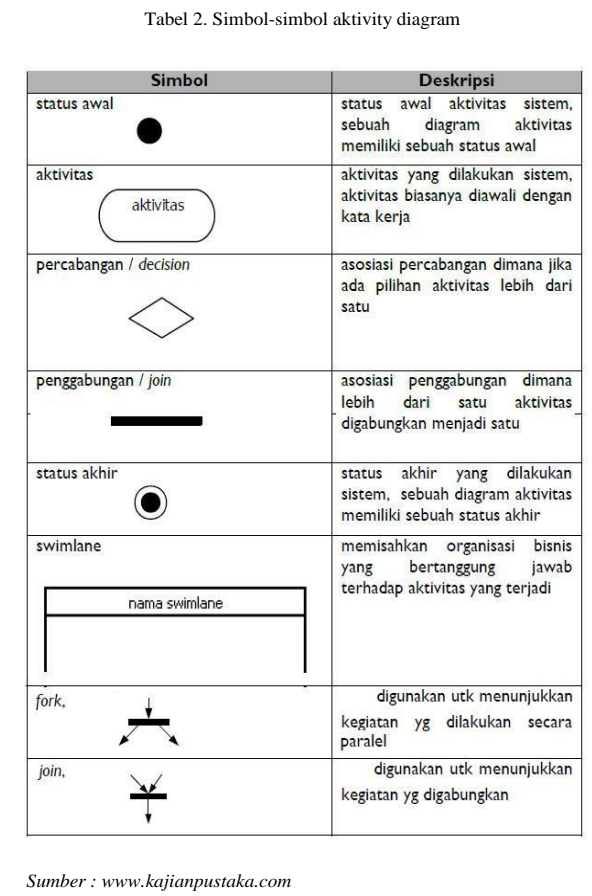

6. UML 


\section{a. Pengertian UML}

UML merupakan singkatan dari "Unified Modelling Language" yaitu suatu metode permodelan secara visual untuk sarana perancangan sistem berorientasi objek, atau definisi UML yaitu sebagai suatu bahasa yang sudah menjadi standar pada visualisasi, perancangan dan juga pendokumentasian sistem software. Saat ini UML sudah menjadi bahasa standar dalam penulisan blue print software.

\section{b. Fungsi UML}

Inilah beberapa tujuan atau fungsi dari penggunaan UML, yang diantaranaya:

1) Dapat memberikan bahasa permodelan visual kepada pengguna dari berbagai macam pemerograman maupun proses rekayasa.

2) Dapat menyatukan praktek-praktek terbaik yang ada dalam permodelan.

3) Dapat memberikan model yang siap untuk digunakan, merupakan bahasa permodelan visual yang ekspresif untuk mengembangkan sistem dan untuk saling menukar model secara mudah.

4) Dapat berguna sebagai blue print, sebab sangat lengkap dan detail dalam perancangannya yang nantinya akan diketahui informasi yang detail mengenai koding suatu program.

\section{c. Jenis-jenis diagram UML}

1. Use case diagram

2. Activity Diagram

3. Sequence diagram

4. Class diagram

5. Statemachine diagram

6. Communication diagram

7. Deployment diagram

8. Component diagram

9. Object diagram

10. Composite structure diagram

11. Interaction Overview Diagram

12. Package diagram

13. Diagram Timing

HASIL DAN PEMBAHASAN

\section{Prosedur Sistem Berjalan}

a. Proses Permintaan Nomor Seri Faktur Pajak

Setiap adanya kegiatan penjualan PT. Semicron Inti muda melakukan rekam faktur baru sesuai dengan Surat Pesanan Barang dan Jasa (SPBJ) dari pihak PT. PLN (Persero). Sebelum pembuatan rekam faktur baru terebih dahulu pihak supervisor dari PT. PLN (Persero) memberikan Surat Pesanan Barang dan Jasa (SPBJ) kepada Admin Pajak.

Lalu admin pajak akan mengecek data pesanan yang sudah di validasi oleh pihak manager PT. PLN (Persero) dan Manager Divison PT. Semicron Inti Muda. Setelah dicek dan data tersebut valid(sama) kemudian admin pajak membuat Permintaan Nomor Seri Fakur Pajak (NSFP) di e-Nofa Online melalui website e-faktur.pajak.go.id. setelah Permintaan Nomor Seri Faktur Pajak (NSFP) berhasil maka admin pajak mencetak surat NSFP.

\section{b. Proses Rekam Faktur PPN baru}

Dalam proses pelaporan rekam faktur pajak yang dilakukan secara online. Rekam pembuatan faktur Pajak Pertambahan Nilai (PPN) dilakukan oleh bagian Administrasi Pajak menggunakan EtaxInvoice. Saat melakukan input rekam pajak keluaran baru dokumen yang dibutuhkan adalah NSFP, SPBJ dan Lampiran SPK, Kemudian baru input fakut pajak baru sesuai dengan dokumen tersebut, setelah di input dan sesuai maka admin akan mengupload faktur pajak tesebut di program EtaxInvoice. Setelah di proses upload berhasil admin akan mencetak PDF faktur.

c. Proses pembuatan Id Billing

Dalam pembuatan Id Billing admin akan membuatnya melalui website resmi Direktorat Pajak yaitu sse.pajak.go.id. lalu admin akan menginput data sesuai dengan Nomor faktur dari dokumen pdf faktur pajak yang telah dicetak. Setelah di input, 
maka admin akan mengecek kembali inputan yang telah dimasukkan.

d. Proses Pelaporan faktur dengan DJP Online

Sebelum admin melakukan pelaporan pajak. Admin akan terlebih dahulu meminta persetujuan kepada $G$. Accounting, dokumen yang diserahkan yaitu Faktur pajak asli, Surat Setoran Elektronik (Id Bliing), SPBJ Asli, SPK Asli, dan NSFP Asli. Lalu setelah di periksa dan disetujui oleh General Accounting dokumen tersebut di scan.

\section{Diagram Analisa Sistem Berjalan}

a. Proses Permintaan Nomor Seri Faktur

Pajak

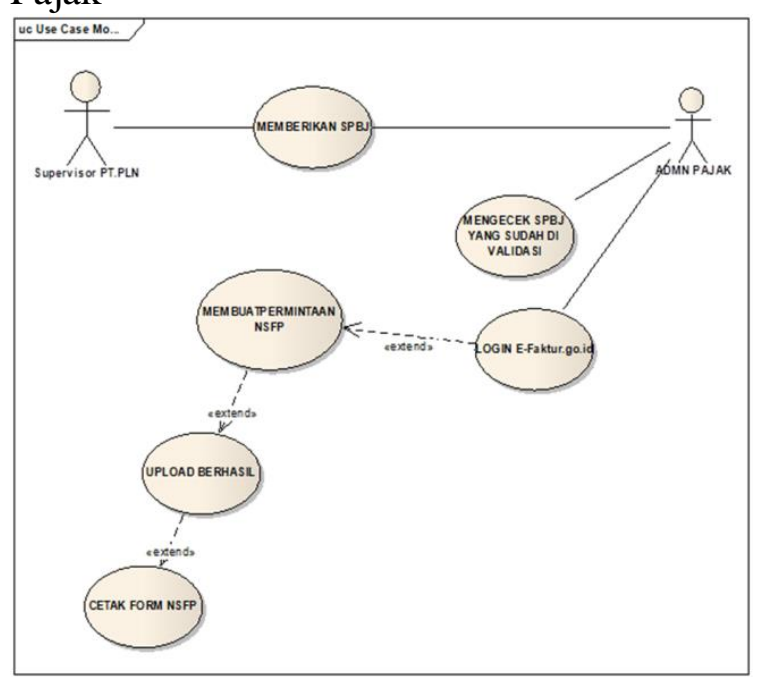

Gambar 1. Permintaan Nomor Seri Faktur Pajak

Use case : Proses Permintaan Nomor Seri Faktur Pajak

Actor 1 : Admin Pajak

Actor 2 : Suvervisor PT. PLN

Pre-Condition : Admin Pajak melakukan rekam faktur baru sesuai dengan Surat Pesanan Barang dan Jasa (SPBJ) dari pihak PT. PLN

Post- Condition: Actor melakukan input rekam pajak keluaran baru dokumen yang dibutuhkan adalah NSFP, SPBJ dan Lampiran SPK,

Description : Actor rekam faktur baru untuk Permintaan Nomor Seri Fakur Pajak (NSFP) di e-Nofa Online setelah Permintaan Nomor Seri Faktur Pajak
(NSFP) berhasil maka admin pajak mencetak surat NSFP.

b. Proses Rekam Faktur baru

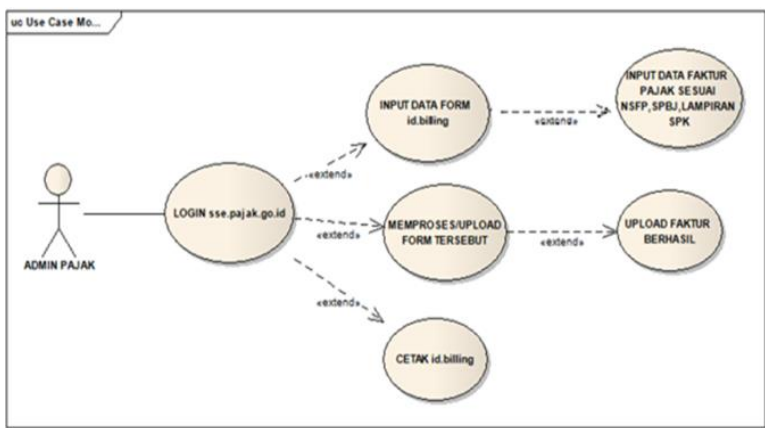

Gambar 2. Rekam faktur baru

Use case : Rekam faktur Baru

Actor : Admin Pajak

Pre-Condition : Actor ingin Menginput dan merekam faktur Baru

Post- Condition : Actor melakukan input rekam pajak menggunakan EtaxInvoice Setelah di proses upload berhasil admin akan mencetak PDF faktur.

Description : Actor melakukan pelaporan pajak menggunakan TaxInvoice..

c. Proses Pembuatan Id Billing

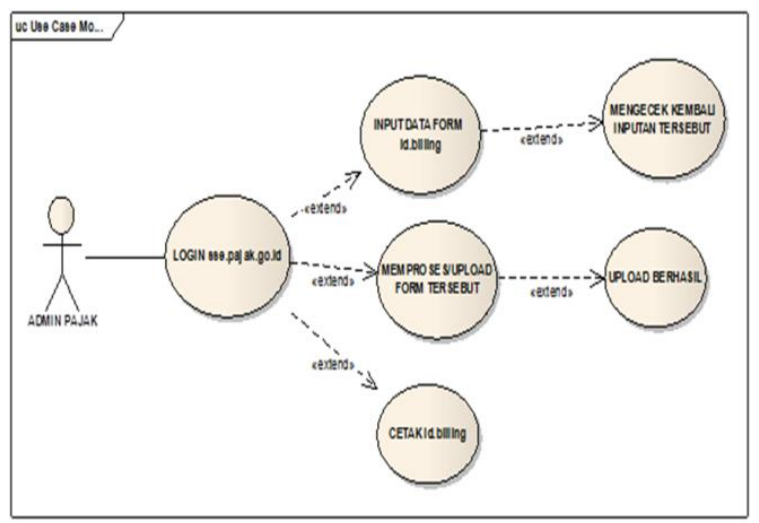

Gambar 3. Pembuatan Id billing

Use case : Proses Pembuatan Id Billing

Actor : Admin Pajak

Pre-Condition : Actor akan menginput data sesuai dengan Nomor faktur dari 
dokumen pdf faktur pajak yang telah dicetak

Post- Condition : Actor admin akan memproses Id billing tersebut, dimana kode NTPN pada id billing tersebut akan dipergunakan untuk melapor faktur pajak kepada Direktorat Jenderal Pajak

Description :Pembuatan Id Billing Actor akan membuatnya melalui website resmi Direktorat Pajak. lalu Actor akan menginput data sesuai dengan Nomor faktur dari dokumen pdf faktur pajak yang telah dicetak.

d. Proses pelaporan faktur pajak dengan DJP Online

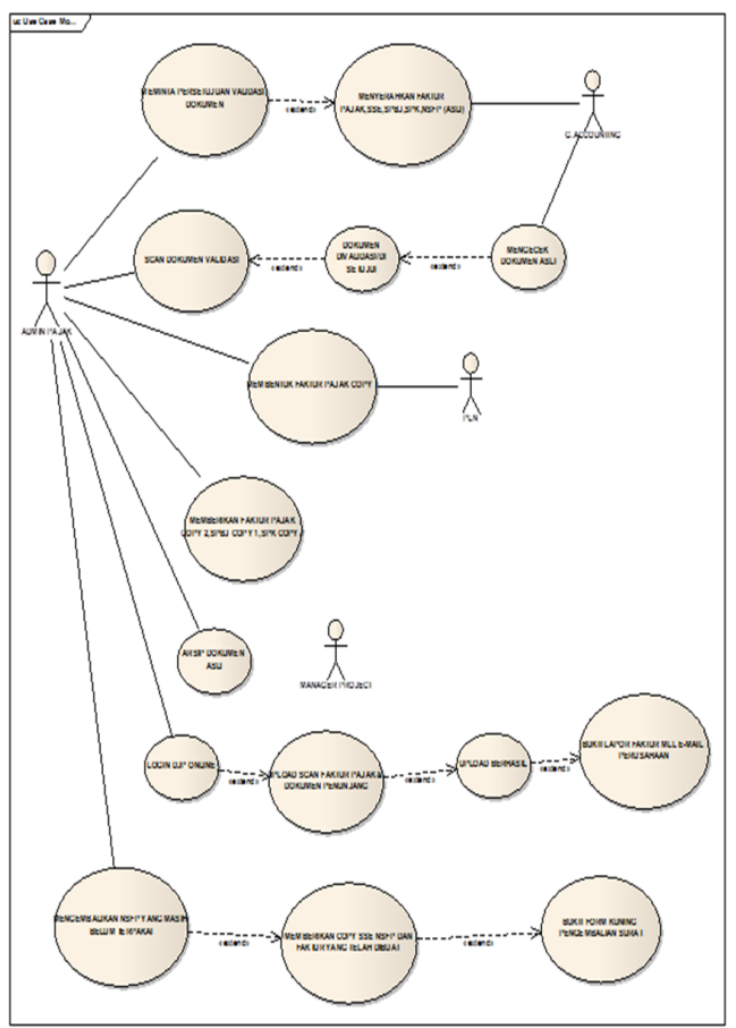

Gambar 4. Pelaporan faktur pajak

\section{Activity Diagram}

Aktivitas diagram pelaporan perekaman faktur pajak PT. SEMICRON INTI MUDA dapat digambarkan sebagai berikut:

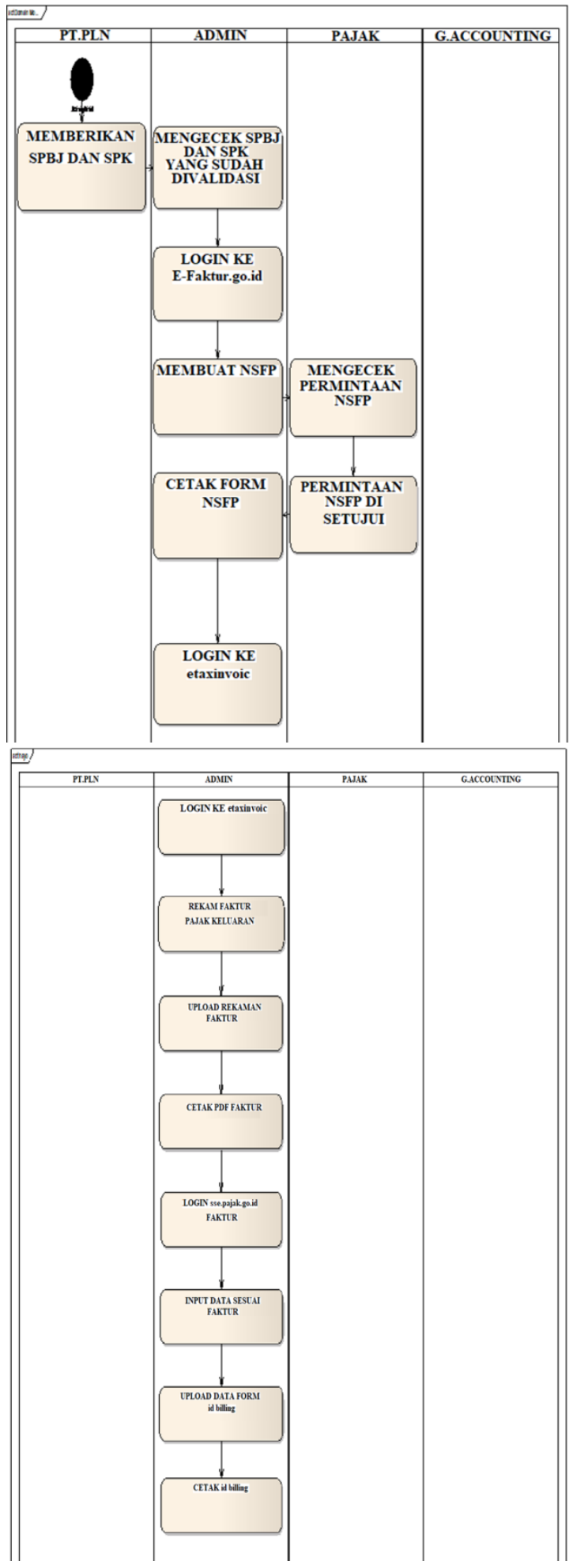




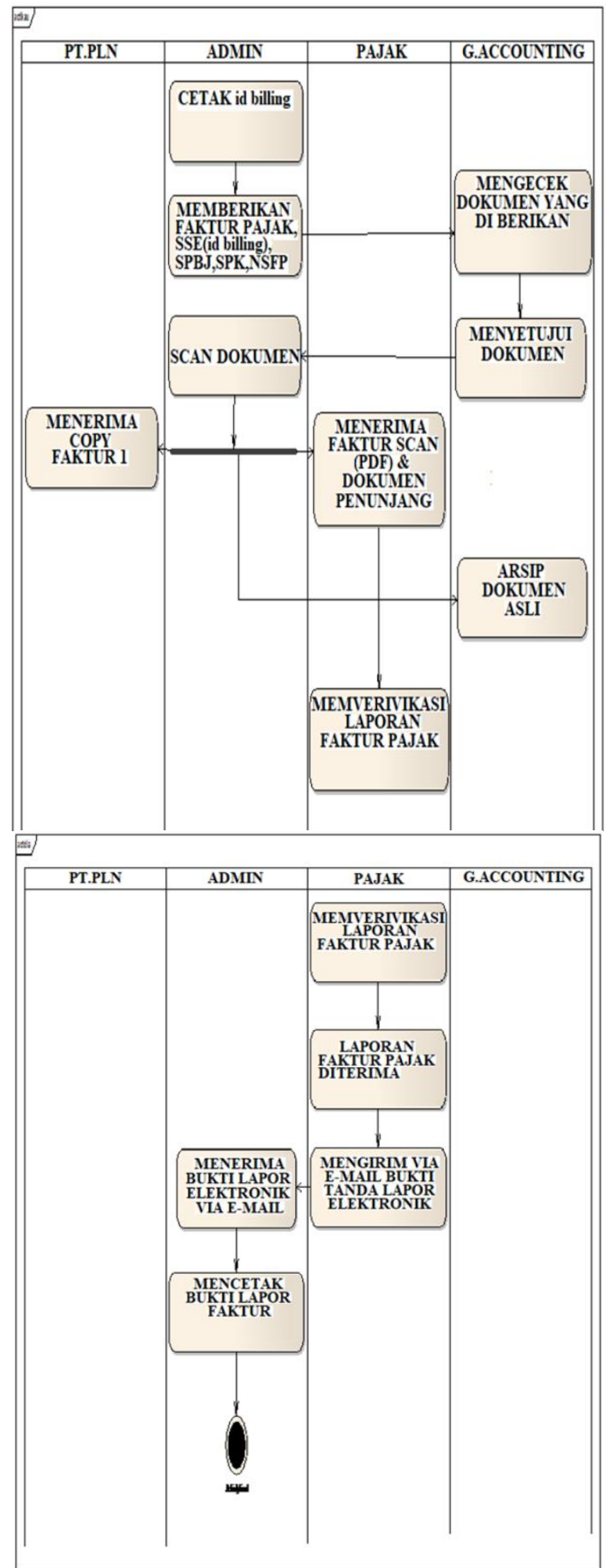

Gambar 5. Activity Diagram

Alur Cerita :

Pada Langkah pertama PT. PLN (Persero) memberikan SPBJ dan SPK kepada PT. Semicron Inti Muda. Kemudian oleh Admin pajak di cek, setelah di cek admin pajak login ke efaktur.go.id untuk membuat NSFP. Setelah NSFP dicetak lalu admin pajak login ke EtaxInvoice untuk membuat faktur baru.
Untuk melapor faktur pajak admin terlebih dahulu membuat Id Billing untuk digunakan pada saat pembayaran PPN atas nilai transaksi kegiatan jual yang dilakukan oleh perusahaan. Admin login ke sse.pajak.go.id untuk membuat id billing. Kemudian admin mencetak Id Billing.

Lalu admin memberikan Faktur pajak, Id Billing, SPBJ, SPK dan NSFP asli kepada G. Accounting lalu G. Accounting mengecek. Jika sudah benar maka di validasi. Lalu Dokumen tersebut diberikan lagi ke admin pajak. Kemudian dokumen tersebut di scan oleh admin. Setelah di scan admin pajak memberikan copy faktur 1 ke PT. PLN (persero), untuk dokumen asli diberikan ke bagian accounting untuk diarsip, dan scan Faktur dan dokumen penunjangnya di upload ke djponline.pajak.go.id.

Lalu dokumen tersebut diverifikasi dan dicheck oleh pajak. Setelah disetujui maka Laporan tanda bukti lapor faktur pajak dikirim via email ke PT. Semicron Inti Muda. Kemudian oleh admin dicetak dan di arsip.

\section{Spesifikasi Sistem Berjalan}

a. Spesifikasi Bentuk Dokumen Masukan

1) Surat Perintah Kerja

Nama Dokumen : Surat Perintah Kerja

Fungsi : Sebagai surat perintah kerja pada pesanan barang dan Jasa

Sumber :Supervisor PT.

PLN (Persero)

Tujuan :Enggineering PT.

Semicron Inti Muda

Media : Kertas

Jumlah : 1 Lembar

Bentuk Dokumen : Lampiran A-1 


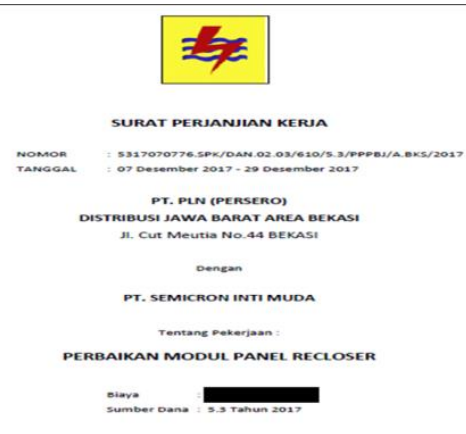

Gambar 6. Surat Perintah Kerja

2) Nomor Seri Faktur Pajak

Nama Dokumen :Nomor Seri Faktur Pajak

Fungsi :Sebagai surat nomor seri faktur pajak untuk digunakan Pada saat membuat faktur pajak baru

Sumber :Direktorat Jendral pajak / website efaktur.pajak.go.id

Tujuan :Administrasi pajak PT.

Semicron Inti Muda

$\begin{array}{ll}\text { Media } & : \text { Kertas } \\ \text { Jumlah } & : 1 \text { Lembar }\end{array}$

Bentuk Dokumen: Lampiran A-1

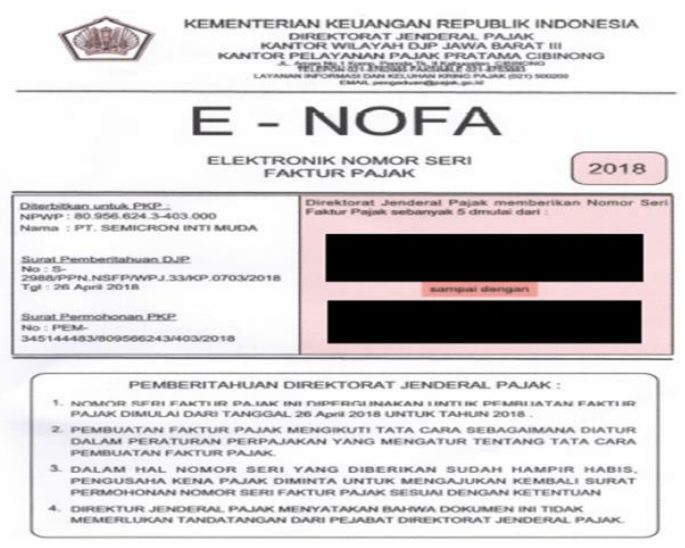

Gambar 7. Nomor Seri Faktur Pajak

3) Surat Pesanan Barang dan Jasa

Nama Dokumen : Surat Pesanan

Barang dan Jasa

Fungsi : Sebagai surat pesanan dari customer untuk digunakan Pada saat membuat faktur pajak dan penagihan

Sumber :PT.PLN (Persero)

Tujuan : Enggineering PT.

Semicron Inti Muda

$$
\begin{array}{ll}
\text { Media } & : \text { Kertas } \\
\text { Jumlah } & : \text { 1 Lembar } \\
\text { Bentuk Dokumen } & : \text { Lampiran A-1 }
\end{array}
$$

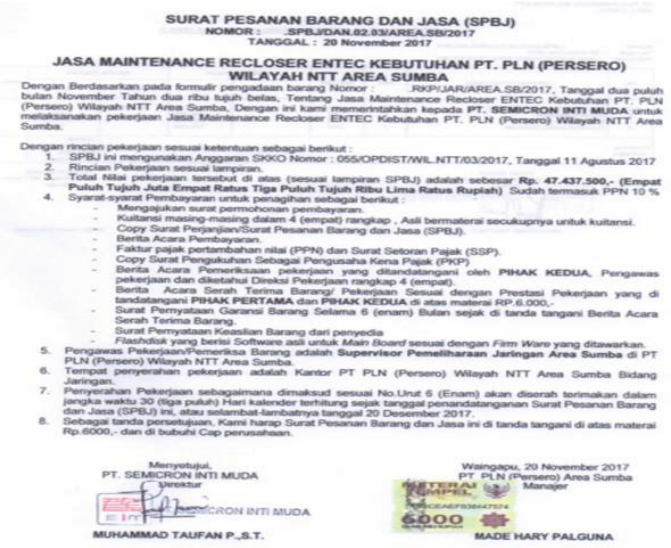

Gambar 8. Surat Pesanan Barang/Jasa

4) Surat Setoran Elektronik (Id Billing)

Nama Dokumen : Surat Setoran Elektronik (Id Billing)

Fungsi : Sebagai surat id billing untuk digunakan pada saat Melakukan pembayaran pajak.

Sumber :Direktorat Jendral pajak / website efaktur.pajak.go.id

Tujuan :Administrasi pajak

PT. Semicron Inti Muda

Media : Kertas

Jumlah : 1 Lembar

Bentuk Dokumen : Lampiran A-1

5) Bukti Lapor Faktur Elektronik

Nama Dokumen: Bukti Lapor Faktur Elektronik

Fungsi : Sebagai surat bukti bahwa perusahaan sudah melaporFaktur pajak.

Sumber :Direktorat Jendral pajak/djponline.pajak.go.id

Tujuan :Administrasi pajak

PT. Semicron Inti Muda

Media : Kertas

Jumlah : 1 Lembar

Bentuk Dokumen : Lampiran A-1

6) Faktur Pajak Masukan

Nama Dokumen: Faktur pajak Masukan

Fungsi : Sebagai surat bukti bahwa perusahaan ada kegiatan 
Usaha dan memenuhi peraturan kewajiban.

Sumber :Direktorat Jendral pajak / EtaxInvoice

Tujuan :Administrasi pajak PT. Semicron Inti Muda

Media : Kertas

Jumlah : 1 Lembar

Bentuk Dokumen: Lampiran A-1

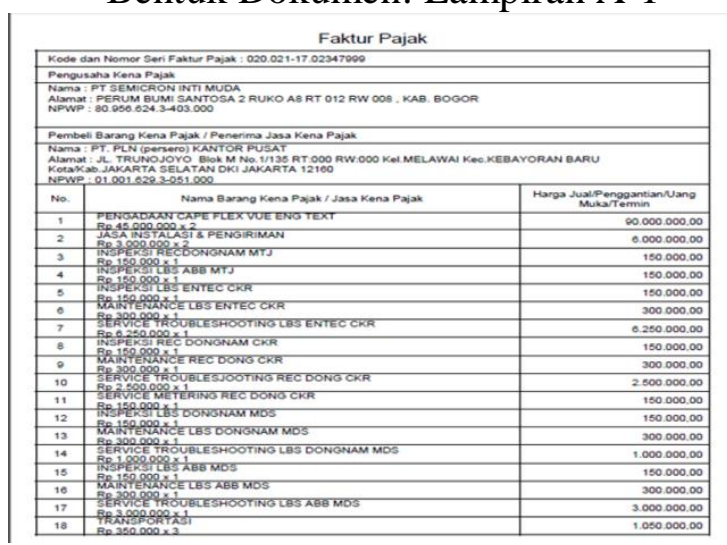

Gambar 9. Faktur Pajak Masukan

b. Spesifikasi Bentuk Dokumen Masukan

1) Surat Perintah Kerja

Nama Dokumen: Faktur pajak

Fungsi : Sebagai surat bukti bahwa perusahaan ada kegiatan usaha dan memenuhi peraturan kewajiban.

Sumber :Direktorat Jendral pajak / EtaxInvoice

Tujuan :Administrasi pajak

PT. Semicron Inti Muda

Media : Kertas

Jumlah : 1 Lembar

Bentuk Dokumen: Lampiran A-1

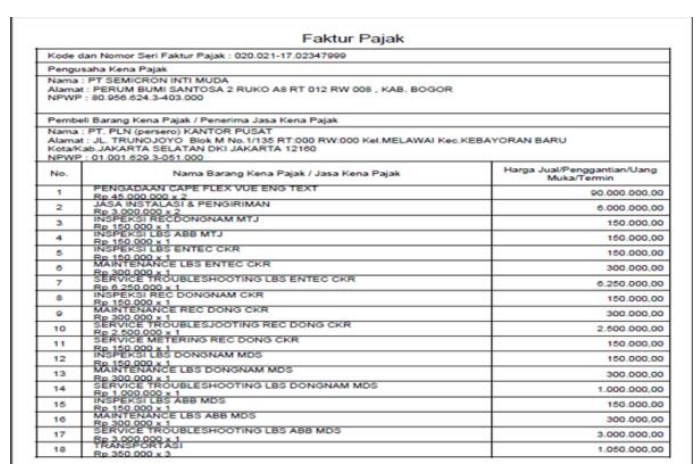

Gambar 9. Faktur Pajak Keluaran

\section{Spesifikasi Sistem Komputer}

a. Sistem Operasi

Sistem operasi yang digunakan adalah System operasi berbasi java sebab System ini menunjang dalam penggunaan aplikasi sistemnya.

a. Sistem Operasi : Etax Invoice

b. Paket program : Berbasis Java yaitu JavaScript

c. Database : EtaxInvoiceUpd.exe,

b. Perangkat Keras

Berikut spesifikasi perangkat keras yang digunakan dalam proses komputerisasi diantaranya :

1. Processor : PC Dell Intell HD Grapic

2. Disk : Flashdisk

3. Memory (RAM) $: 8 \mathrm{~GB}$

4. Monitor : LCD 17

5. Hardisk : $160 \mathrm{~GB}$

\section{Permasalahan}

Setelah melakukan observasi kepada pimpinan PT. Semicron Inti Muda ternyata ada beberapa kendala yang kadang-kadang terjadi pada saat melaukan perekaman dan pelaporan faktur pajak. Kendala tersebut meliputi:

a. Kurang telitinya administrasi dalam menginput pada saat rekam faktur pajak baru.

b. Dalam kegiatannya sistem yang digunakan bergantung pada system online resmi Direktorat Jendral Pajak, sehingga dapat memakan waktu yang lama.

c. Pada sistem berupa aplikasi online memerlukan jaringan internet, dimana terkadang jaringan mengalami error.

Pada program Etax Invoice program sering mengalami kendala lemot.

\section{Alternatif Pemecahan Masalah}

Setelah mengamati permasalahan yang ada di PT. Semicron Inti Muda penulis menyimpulkan bahwa sistem yang digunakan oleh perusahaan masih kurang baik. Maka penulis membuat alternatif pemecahan masalah sebagai berikut: 
a. Perlu sumber daya manusia yang ahli dalam bidang pajak.

b. Menggunakan jaringan internet yang high quality agar tidak ada masalah jaringan error.

c. Sebaiknya menggunakan aplikasi online pajak berbayar. Karena dapat lebih mudah dan hanya dalam satu aplikasi semua urusan pajak dapat kita kerjakan tanpa perlu ke sistem lainnya.

\section{KESIMPULAN DAN SARAN}

Faktur pajak merupakan bukti bahwa PKP telah melakukan penyetoran, pemungutan, dan pelaporan SPT masa PPN sesuai dengan peraturan yang berlaku.

Jika terjadi kesalahan dalam mengisi faktur pajak, PKP dapat melakukan pembetulan faktur pajak tersebut.Jika tidak dilakuakan pembetulan sama sekali, maka hal ini akan merugikan PKP yakni pada saat Audit datang ke PKP dan melakukan pemeriksaan pajak.

E-Faktur aplikasi Pajak Online yang user-friendly dan hemat waktu.sinkronisasi Nomor seri faktur pajak dengan akun ENova,mendapatkan E-Faktur,Hitung,Setor dan lapor PPN semua di lakukan dalan satu aplikasi saja.

\section{Saran-Saran}

a. Adanya penambahan fitur toolbar pada aplikasi E-faktur pajak, agar Saat status ppn kurang bayar, id billing bisa langsung muncul pada jendela nomor ntpn.

b. Adanya penambahan fitur toolbar pada aplikasi E-faktur Pajak, untuk penambahan cetak nomer resi faktur id billing pada toolbar Sehingga Wajib Pajak dapat membayar langsung menggunakan nomer id billing yangg tercantum pada jendela informasi pada toolbar aplikasi tersebut.

c. Adanya penambahan fitur toolbar pada aplikasi E-Faktur pajak,untuk penambahan Notifikasi (pemberitahuan) untuk Sertifikat E-
Faktur yang memiliki masa aktif selama 1 tahun dan Wajib Pajak, wajib melakukan aktivasi kembali atas sertifikat e faktur tersebut.

\section{DAFTAR PUSTAKA}

A.S, Rosa et al., 2016, "Rekayasa Perangkat Lunak", Penerbit Informatika, Bandung

Amstrong, Michael, 2018, "Sistem Penggajian", Penerbit Kencana, Jakarta

Munawar, 2017, "Analisa Perancangan Sistem Berorientasi Objek dengan UML", Penerbit Informatika, Bandung

Tohri, Hamin, 2017, “Analisis serta Perancangan Sistem Informasi melalui Pendekatan UML", Penerbit Andi Offset, Jakarta

TMBooks, 2015, "Sistem Informasi Akuntansi", Penerbit Andi Offset, Jakarta

Munawar, 2017, “Analisa Perancangan Sistem Berorientasi Objek dengan UML", Penerbit Informatika, Bandung

Yani, Ahmad, 2006, "Solusi Masalah Pajak Pertambahan Nilai", Penerbit Kencana Prenada Media Group, Jakarta 